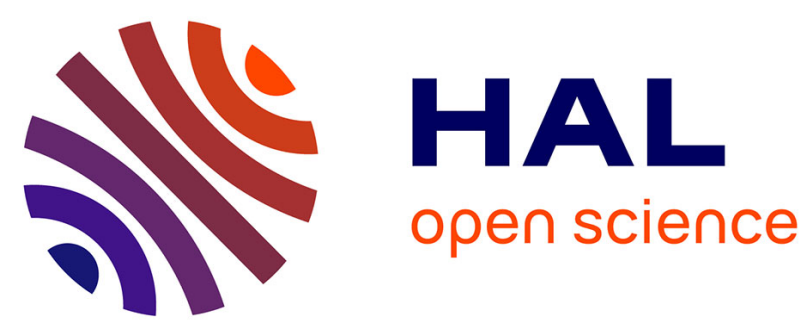

\title{
Porous materials applied to biomarker sensing in exhaled breath for monitoring and detecting non-invasive pathologies
}

Laurie André, Nicolas Desbois, Claude P Gros, Stéphane Brandès

\section{- To cite this version:}

Laurie André, Nicolas Desbois, Claude P Gros, Stéphane Brandès. Porous materials applied to biomarker sensing in exhaled breath for monitoring and detecting non-invasive pathologies. Dalton Transactions, 2020, 49 (43), pp.15161-15170. 10.1039/D0DT02511A . hal-03480297

\section{HAL Id: hal-03480297 https://hal.science/hal-03480297}

Submitted on 14 Dec 2021

HAL is a multi-disciplinary open access archive for the deposit and dissemination of scientific research documents, whether they are published or not. The documents may come from teaching and research institutions in France or abroad, or from public or private research centers.
L'archive ouverte pluridisciplinaire HAL, est destinée au dépôt et à la diffusion de documents scientifiques de niveau recherche, publiés ou non, émanant des établissements d'enseignement et de recherche français ou étrangers, des laboratoires publics ou privés. 


\title{
Porous materials applied to biomarkers sensing in exhaled breath for monitoring and detecting non-invasive pathologies
}

\author{
Laurie André,* Nicolas Desbois, Claude P. Gros* and Stéphane Brandès \\ The quantification of specific gases among thousand of VOCs (Volatile Organic Compounds) present in the human breath at the ppm/ppb level \\ can be used to evidence the presence of diseases in the human body. The detection of these biomarkers in human exhaled breath through a \\ noninvasive approach is an important field of research which is still attracting important attention to this day. A portable device working at \\ room temperature and usable directly on exhaled breath samples is still a challenge requiring a sensing material with high performances. The \\ rich composition of the human breath implies that the sensing material must be highly selective and sensitive (ppm/ppb) in high relative \\ humidity $(\mathrm{RH})$ conditions and preferably at room temperature. The present work intends to provide a review on recent works in this application \\ field through the use of porous materials and discuss the interest of Metal Organic Frameworks (MOFs) for such application. MOFs are highly \\ porous crystalline materials often used for gas detection and capture, thus raising the question of their potential for detection in exhaled \\ breath.
}

\section{Introduction}

A number of pathologies can be detected through the capture and quantification of biomarkers (e.g. acetone, ${ }^{1-3}$ ammonia, ${ }^{4,5}$ nitrites, ${ }^{6}, 7$ hydrogen sulphide, $\left.{ }^{8-11} \ldots\right)$ in human exhaled breath. ${ }^{12-18}$ Biomarkers can be identified after an imbalance in the chemical composition of the blood or breath, and appears as a result of organs dysfunction or diseases present in the human body. Their early detection can be used to reveal an anomaly in the early stages of the disease, and can help monitoring a treatment's progress. For instance, kidney or liver disorders can be detected through an abnormal amount of ammonia released in the blood which diffuses into the breath, and early detection can help for an on-time transplant, in case of renal insufficiency, with then higher rates of success. The presence of ammonia in a healthy human breath ranges from $500 \mathrm{ppb}$ to $2100 \mathrm{ppb}$, while the amount measured in unhealthy patient from renal disease ranges from 0.82 to 14.7 ppm. ${ }^{4,5}$ Another example is the detection of elevated levels of acetone in breath which can be a hint to high glucose levels in the blood related to diabetes due to a disturbance in the amount of insulin. Indeed, the acetone concentration in the exhaled breath of diabetic patients is generally higher than $1.8 \mathrm{ppm}$, while the concentration of acetone gas in exhaled breath of healthy individuals is less than 0.9 ppm. ${ }^{1-3}$ Early detection of cancer is also of primary interest and exhaled breath analysis has been recently considered as a way of detection. ${ }^{19-23}$ Recent researches multiply careful studies of variations in exhaled breath VOCs compositions in order to identify biomarkers which could testify for the development of lung cancer, ${ }^{24-31}$ breast cancer, ${ }^{32}$ head and neck cancer (HNC) ${ }^{33}$ or gastric cancer. ${ }^{34} \mathrm{~A}$ portable biomarker sensor, requiring only sample exhaled breath from patients, and with a rapid response, is a very attractive option to add at the disposal of practitioners to help them and their patients to fight against a set of diseases. The study and development of gas sensors over the years has highlighted the potential of organic, inorganic and hybrid ${ }^{35}$ materials for this application. However, despite the years of research which have led to highly specific and accurate gas analysis methods and sensors, work is still on-going for the development of a convenient, non-invasive, affordable and easy to carry exhaled breath sensors for the detection of pathologies. ${ }^{13}$ Furthermore, for on-site and direct analysis, it would be interesting to have access to gas sensors compatible with the as-obtained exhaled breath samples, which means a high sensitivity and selectivity at low temperature $\left(20-37^{\circ} \mathrm{C}\right)$ and high relative humidity $(\mathrm{RH})$, together with a short response time and recovery time for on-site diagnosis. Porous materials are often studied for gas sensing applications and are thus of great interest for gas biomarkers in exhaled breath. Among them, Metal Organic Frameworks (MOFs) have attracted considerable attention for their very high porosity and unique tunable structures. In fact, MOFs have been abundantly studied for protection against chemical warfare agents and for the capture and removal of toxic chemicals in air. ${ }^{36-40}$ The capture of chemicals such as $\mathrm{NH}_{3}, \mathrm{H}_{2} \mathrm{~S}$ and $\mathrm{NO}_{x}$ using MOFs is promising for application in the detection of biomarkers in exhaled breath. The properties of MOFs combined with efficient gas sensing devices could provide an interesting approach to the adaptation of gas sensors to the need of a portable breath analyser in the medical field. As many uses for MOFs have been developed in recent years, the present article aims to present recent works based on porous materials and to discuss the potential of MOFs concerning their potential applications as gas sensors for biomarkers and disease detection based on the latest advancements.

Introduction to sensing methods 
Several approaches are being considered for the analysis of breath samples such as GC/MS (Gas Chromatography and Mass Spectrometry), SIFT-MS (Selected-Ion Flow-Tube Mass Spectrometry), PTR-MS (Proton Transfer Reaction Mass Spectrometry), resistance response and optic response variations. As a result, many different sensor types are being developed for VOCs analysis (Fig. 1). ${ }^{41}$ Gas chromatography is the most commonly used and most efficient gas analysis method but is not compatible with a portable device for cheap on-site analyses. ${ }^{22}$ Indeed, gas chromatography and mass spectrometry methods are expensive, require equipment which is difficult to move around, a strong power source, and need experimented operators. However, these methods remain efficient to analyse a complex mixture of gases.

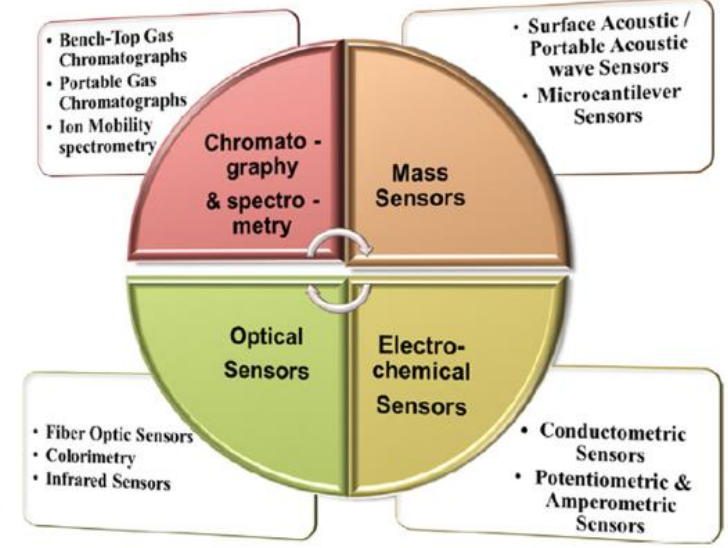

Figure 1. Different sensor types used for volatile organic compounds (VOCs) analysis, reproduced with permission from $\left[{ }^{41}\right]$ Copyright (2020) Elsevier.

Within the reviewed studies, the sensitivity of the sensing material refers to the minimum volume concentration at which the analyte, the chemical species of interest, is detected. Selectivity is tested for a specific set of analytes among other interferent gases, as the human breath holds a complex gas composition and high humidity. In addition, the response time provides the time needed for the sensor to reach the required concentration to give a signal. Another approach is to coat interdigitated electrodes with the gas sensing material and measure variations of conductivity within the device due to its interaction with the adsorbed analyte. ${ }^{42-44}$ The performance of a gas sensor can be measured relatively to the variation in conductivity vs an electrical current in the sensing layer in the reference gas. Another way is to use a quartz microbalance (QCM) in combination with a sensing material. ${ }^{45} \mathrm{~A}$ quartz crystal microbalance is based on a piezoelectric material for which it's oscillation frequency will vary upon adsorption of the analyte, and thus weight variation, and the determination of this frequency shift can then be linked directly to the sensitivity of the material towards the analyte. The detection of the analyte adsorption on sensing materials can also be observed using optical methods, such as fluorescence quenching of the material or its variation in colour or luminescence. ${ }^{46-48}$ The fluorescence quenching following the adsorption of the target gas can be used for a rapid identification, and a luminescence shift can be measured, indicating the adsorption of the expected biomarker. Some of the devices requiring a light source might be difficult to miniaturize. In addition, a significant change of colour presents the advantage of instant identification by the naked eye, but also presents a quantification issue. In the meantime, significant work has progressed concerning a type of sensing device, the electric nose (e-nose), which is a cascade combination of several systems. ${ }^{12,}$,9-52

\section{Sensors based on polymers and organic materials}

In recent works, polymers have been studied for the detection of biomarkers and present the advantage that they do not require high temperature to enhance their sensitivity to the analyte. They are thus well suited for the fabrication of room temperature gas sensors. ${ }^{51}$ For example, polymers such as polyvinylpyrrolidone) (PVP), ${ }^{53}$ or acid-doped polypyrrole coating on filter paper ${ }^{54}$ were investigated for the detection of ammonia. Another example is 2,4-dinitrophenylhydrazine (DNPH) deposited on the micropillars of a microreactor chip that was used as a sensor for traces of carbonyl compounds including ketones in breath. ${ }^{55}$ The fabrication of an organicbased acetone sensor working at room temperature was also considered by using poly[(9,9-dioctylfluorenyl-2,7-diyl)-co$\left(4,4^{\prime}\right.$-( $N$-(4-sec-butylphenyl)diphenylamine)] (TFB), but the material was also sensitive to the presence of ammonia.56 Recently, a biomass hydrogel based on poly-L-glutamic acid and L-glutamic acid (PGA/GA) was synthesized and demonstrated good performances for the detection of ammonia $(0.5 \mathrm{ppm})$ at room temperature under high relative humidity $(80 \%) .{ }^{57}$

\section{Sensors based on metal oxides}

Semiconductor Metal Oxides (MOs) have interesting physical and chemical properties that are size dependent. ${ }^{35,58-60} \mathrm{MOs}$ with nanometric dimensions $(1-100 \mathrm{~nm})$ present remarkable electrical and chemical properties, high specific surface area and high surface to volume ratio which is greatly desired for a wide range of applications specially for VOCs gas sensors. ${ }^{60}$ As the analyte gas comes into contact and reacts with the metal oxide surface thanks to a redox process, the resistance of the sensor is modified. Metal oxide-based sensors show higher conductivity at higher temperatures, as it promotes the reaction between the gas and the surface of the material. These materials present great sensitivity and allow the precise detection on the ppm and ppb level, but require a high temperature $\left(200-400{ }^{\circ} \mathrm{C}\right)$. However, challenges remain to be overcome for the development of highly performant chemiresistive sensors. ${ }^{59}$ Pure metal oxides and doped metal oxides were studied for the specific detection of biomarkers in exhaled breath. For example, the performances of $\mathrm{WO}_{3}$ and Si-doped 
$\mathrm{WO}_{3}$ detector films, made from nanoparticles synthesized in gas phase and directly deposited on interdigitated electrodes, were studied for the detection of acetone in synthetic samples representing healthy and diabetes diagnosed patients' breath. ${ }^{61}$ A micro analytical device for the detection of lung cancer biomarkers (toluene, $o$-xylene, propanol and cyclohexane) based on a Al-Si metal oxide was developed. ${ }^{29}$ The experiments were done at room temperature $\left(25^{\circ} \mathrm{C}\right)$, measuring the influence of the high concentration of interfering gases such as water vapor $(100 \% \mathrm{RH})$ and $\mathrm{CO}_{2}(40000 \mathrm{ppm})$. Another example in recent studies is the comparison of the $\mathrm{H}_{2} \mathrm{~S}$ sensing performances (at ppb level, $200{ }^{\circ} \mathrm{C}$ ) of $\mathrm{Fe}_{2} \mathrm{O}_{3}$ nanomaterials derived from Prussian blue. ${ }^{10}$ The experiments reveal that material as nanospheres present the best sensing performances, before nanocubes, and lastly nanoflower shaped particles. The enhancement of flower-like porous $\mathrm{SnO}_{2}$ material for acetone sensing was achieved using the high surface activity of added Pt nanoparticles. ${ }^{62}$ The material was able to show a sensing response at $153{ }^{\circ} \mathrm{C}$ for $100 \mathrm{ppm}$ to $50 \mathrm{ppb}$. More complex systems including heterojunctions are also attracting attention for breath analysis application. ${ }^{42,}{ }^{63-66}$ As an example, Marigold flower-like $\mathrm{V}_{2} \mathrm{O}_{5} / \mathrm{CuWO}_{4}$ heterojunctions were recently studied for the detection of ammonia in exhaled breath. ${ }^{42}$ As another example, the $\alpha-\mathrm{Fe}_{2} \mathrm{O}_{3}-\mathrm{SnO}_{2}$ heterostructure consisting of $\mathrm{Fe}_{2} \mathrm{O}_{3}$ nanorods dispersed in nanosheet arrays displayed good acetone sensing properties (high sensitivity, reproducibility, and selectivity). ${ }^{67}$ The sensing performances of the material were tested for $5 \mathrm{ppm}$ at $340{ }^{\circ} \mathrm{C}$ under varying percentage of $\mathrm{RH}(20,40,60,80$, and $90 \%)$. Further improvement based on $\mathrm{ZnSnO}_{3} / \alpha-\mathrm{Fe}_{2} \mathrm{O}_{3}$ material, in the form of urchin-like hierarchical hollow microspheres, was achieved for the detection of acetone at $200{ }^{\circ} \mathrm{C} .68$

\section{Organic-inorganic hybrid materials}

The synthesis of hybrid materials is a way to address the many challenges posed by the conditions required to detect specific biomarkers in exhaled breath, by making the most of organic and inorganic sensing materials. ${ }^{35,69}$ As an example, polyaniline (PANI) based hybrids combined with metal oxides $\left(\mathrm{TiO}_{2}, 51,70\right.$ $\mathrm{SnO}_{2},{ }^{71} \mathrm{In}_{2} \mathrm{O}_{3},{ }^{72} \mathrm{ZnO},{ }^{73} \mathrm{CeO}_{2}{ }^{74}$ ) are being studied for the detection of ammonia at room temperature. An array of 11 different polyaniline-based sensors were studied for the detection of ammonia for the identification of kidney failure. ${ }^{51}$ The polyaniline was combined with either chitosan, $\mathrm{TiO}_{2}$ or multi-wall carbon nanotubes (CNTs), and polyaniline was doped with 4-dodecylbenzenesulfonic acid (DBSA), to make a nanocomposite sensing layer deposited on chrome/gold interdigitated electrodes. Recently, Diouf et al. ${ }^{7}$ have developed a gas sensor based on ion imprinted polymer and gold nanomaterials demonstrating a good selectivity for nitrite ions, against nitrate, acetate and ammonium nitrate, for application in exhaled breath condensate. Selective chemical sensors working at room temperature could also be achieved with highly porous $\mathrm{SnO}_{2}$-graphene oxide nanoheterojunctions layouts. ${ }^{75}$ Varying the amount of graphene oxide in the $\mathrm{SnO}_{2}$ nanoparticles network was shown to change the selectivity of the material. For instance, the selectivity was enhanced towards ethanol with low graphene oxide amounts, while the presence of high amounts of graphene oxide hindered the detection of ethanol instead, and raised the selectivity towards ethylbenzene.

\section{Porous materials for biomarkers sensing in exhaled breath}

Further improvement of gas sensors can be reached using porous structures to increase the selectivity and adsorption capacity of gas sensing materials. For instance, hemitubes network made from Pt-functionalized $\mathrm{WO}_{3}$ were synthesized and studied for the detection of acetone in exhaled breath. ${ }^{76}$ Hemitubes networks were prepared by $\mathrm{WO}_{3}$ sputtering on polymer nanofibers as sacrificial template, allowing to control the tubes wall thickness through the sputtering time. The surface of the obtained material was then decorated with $\mathrm{Pt}$ nanoparticles. The Pt-functionalized $\mathrm{WO}_{3}$ hemitubes showed enhanced sensing performance towards acetone, while the monitored response to $\mathrm{H}_{2} \mathrm{~S}$, toluene and ethanol was negligible. Pt-decorated porous $\mathrm{SnO}_{2}$ nanotubes were also synthesized and studied for the detection of acetone in simulated diabetes breath. ${ }^{77}$ The combination of electrospinning using polystyrene (PS) colloid as sacrificial template permitted access to a bimodal pore distribution in the material, with the thin-wall of the nanotubes presenting both mesopores and macropores, facilitating the gas diffusion into the sensing layer. The resistivity of the sensing layer was measured in healthy patient's exhaled breath and in simulated diabetic breath containing several interfering gases (hydrogen sulphide, toluene, nitrogen monoxide, ammonia, carbon monoxide, methane, hydrogen and pentane). An heterostructure made of p-type $\mathrm{Co}_{3} \mathrm{O}_{4}$ sensitized n-type $\mathrm{SnO}_{2}$ porous nanospheres also showed high selectivity and sensitivity towards acetone. ${ }^{78}$ In their study, Zhang et al. ${ }^{79}$ focused on the adaptation of $\mathrm{CO}_{3} \mathrm{O}_{4}$ based acetone sensors for lower temperature application, using hollow carbon spheres combined with $\mathrm{Co}_{3} \mathrm{O}_{4}$ nanowires to form a mesoporous gas sensor material $\left(\mathrm{CO}_{3} \mathrm{O}_{4} \mathrm{NWs}-\mathrm{HCSs}\right)$.

\section{MOF-derived metal oxide-based sensors}

In recent studies, MOFs have been used as templates for the synthesis of efficient porous metal oxide-based gas sensors. The Hollow $\mathrm{SnO}_{2}$ nanotubes have been combined with a PdO-ZnO composite for the detection of acetone, ${ }^{80}$ using the well-known MOF ZIF-8, belonging to the zeolite imidazole framework family, for the catalyst loading on $\mathrm{SnO}_{2}$ nanotubes. ZIF-8 was first loaded with $\mathrm{Pd}$ nanoparticles before being used as a template for the deposition of PdO@ZnO catalyst onto the nanotubes surface by electrospinning. Pt nanoparticles were also deposited on highly dispersed MOF-derived microporous ZnO and studied for the detection of $\mathrm{H}_{2} \mathrm{~S} .{ }^{81}$ With a $1 \mathrm{wt} \% \mathrm{Pt}$ 
nanoparticles loading in Pt@ZIF-8, the MOF-derived Pt/ZnO sensor presented a good response towards $1 \mathrm{ppm} \mathrm{H}_{2} \mathrm{~S}$ in air, with good selectivity and stability. The combination of cobaltdoped ZnO particles derived from ZIF MOF is currently raising interest as it demonstrated promising performances for the detection of diabetes biomarker. Optimized Zn/Co mixed oxide nanoparticles, with $5 \mathrm{~mol} \% \mathrm{Co}$, showed high selectivity towards $5 \mathrm{ppm}$ acetone between simulated diabetic breath and healthy exhaled breath samples. ${ }^{82}$ Another example is the synthesis of hollow nanocages made of $\mathrm{Co}_{3} \mathrm{O}_{4}$ and loaded with $\mathrm{PdO}$ nanoparticles by using the MOF ZIF- 67 as template. ${ }^{83}$ This way of synthesis gives catalyst functionalized cobalt oxide with better response to acetone sensing $\left(R_{\text {gas }} / R_{\text {air }}=2.51-5 \mathrm{ppm}\right)$ than $\mathrm{Co}_{3} \mathrm{O}_{4}$ and $\mathrm{PdO}-\mathrm{CO}_{3} \mathrm{O}_{4}$ powders. $\mathrm{CO}_{3} \mathrm{O}_{4}$ derived from MOF ZIF-67 was also used as a way to functionalize graphene oxide hydrogels with $\mathrm{CO}_{3} \mathrm{O}_{4}$, forming together a porous composite with enhanced response and selectivity to acetone. In addition, $\mathrm{CO}_{3} \mathrm{O}_{4}$ derived from Co-MOF-74 was combined with graphene oxide to form $\mathrm{CO}_{3} \mathrm{O}_{4}$ /graphene heterojunction nanoscrolls (Fig.

2) for the sensing of acetone at low concentration levels. ${ }^{65}$

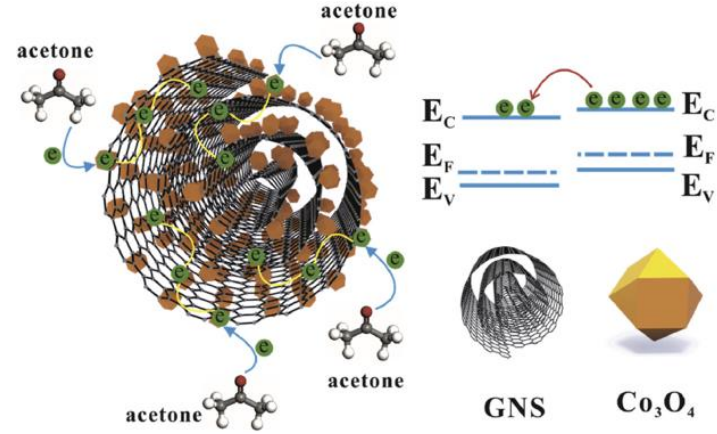

Figure 2. Acetone-sensing mechanism of $\mathrm{CO}_{3} \mathrm{O}_{4} / \mathrm{GNS}$ (graphene heterojunction nanoscrolls) based sensor, reproduced with permission from [65] Copyright (2020) Elsevier.

Table 1. Recently researched MOFs for application in biomarker detection in exhaled breath.

\begin{tabular}{|c|c|c|c|c|c|c|}
\hline Biomarker & Pathology & MOF-based material & $\begin{array}{c}\text { Detection limit } \\
\text { or lowest } \\
\text { concentration tested }\end{array}$ & $\begin{array}{l}\text { Relative } \\
\text { humidity }\end{array}$ & $\begin{array}{c}\text { Working } \\
\text { Temperature } \\
\left({ }^{\circ} \mathrm{C}\right)\end{array}$ & Ref. \\
\hline Acetone & Diabetes & $\begin{array}{l}\text { ZIF-90 } \\
\text { UiO-66 } \\
\text { UiO-66* }\end{array}$ & $\begin{array}{c}20 \mathrm{ppb} \\
2.79 \mathrm{ppm} \\
0.79-0.84 \mu \mathrm{L} \mathrm{L}^{-1}\end{array}$ & $\begin{array}{c}11.3-97.8 \% \\
90 \% \\
\text { Dry } \mathrm{N}_{2}\end{array}$ & $\begin{array}{c}\mathrm{RT} \\
253 \\
240\end{array}$ & $\begin{array}{l}45 \\
106 \\
105\end{array}$ \\
\hline Aldehydes & Cancers & $\begin{array}{l}\text { ZIF-7 on stainless fiber* } \\
\text { ZIF-8 } \\
\text { POM@ZIF-8@ZnO } \\
\text { Zn(NA) (NA=nicotinic acid) } \\
\text { Zn(INA) (INA=isonicotinic acid) } \\
\text { Gold superparticles@ZIF-8 } \\
\text { SERS substrate* }\end{array}$ & $\begin{array}{c}0.61-0.84 \mu \mathrm{g} \mathrm{L}^{-1} \\
25 \mathrm{ppm} \\
0.4 \mathrm{ppm} \\
10 \mathrm{ppm} \\
10 \mathrm{ppm} \\
10 \mathrm{ppb}\end{array}$ & $\begin{array}{c}\text { Dry } \mathrm{N}_{2} \\
\text { Dry air } \\
\text { 33, 54, } 75,84,97 \% \\
\text { Dry air } \\
\text { Dry air } \\
\text { 0, 50, } 80,100 \%\end{array}$ & $\begin{array}{c}250 \\
\text { RT } \\
\text { RT } \\
\text { RT } \\
\text { RT } \\
\text { RT, } 50,100\end{array}$ & $\begin{array}{r}107 \\
89 \\
92 \\
89 \\
89 \\
109\end{array}$ \\
\hline Ammonia & $\begin{array}{l}\text { Renal failure, } \\
\text { liver } \\
\text { dysfunction, } \\
\text { halitosis }\end{array}$ & $\begin{array}{l}\text { NDC-Y-fcu-MOF (Naphtalene-based) } \\
\text { ZIF-8 } \\
\text { Zn(NA) (NA=nicotinic acid) } \\
\text { Zn(INA) (INA = isonicotinic acid) } \\
\text { L-Glu-Co, L-Glu-Ni, L-Glu-Cu }\end{array}$ & $\begin{array}{l}100 \mathrm{ppb} \\
10 \mathrm{ppm} \\
10 \mathrm{ppm} \\
10 \mathrm{ppm} \\
-\end{array}$ & $\begin{array}{l}5-85 \% \\
\text { Dry air } \\
\text { Dry air } \\
\text { Dry air } \\
\quad \text { Air }\end{array}$ & $\begin{array}{l}\text { RT } \\
\text { RT } \\
\text { RT } \\
\text { RT } \\
\text { RT }\end{array}$ & $\begin{array}{l}44 \\
89 \\
89 \\
89 \\
95\end{array}$ \\
\hline $\begin{array}{l}\text { Hexanal Ethylbenzene } \\
\text { 1-propanol }\end{array}$ & Lung cancer & Modified ZIF-8@amine & $\begin{array}{c}1 \mathrm{ppb} \\
\text { (Hexanal) }\end{array}$ & In solution & RT & 90 \\
\hline Nitrite ion & $\begin{array}{l}\text { Inflammation } \\
\text { response }\end{array}$ & {$\left[\mathrm{Tb}_{2}(\mathrm{TTHA})\left(\mathrm{H}_{2} \mathrm{O}\right)_{4}\right] \cdot 9 \mathrm{H}_{2} \mathrm{O}$} & $\begin{array}{c}0.732 \\
\mathrm{~L}_{\text {control }} / \mathrm{L}_{\text {sample }} \mu \mathrm{g}^{-1}\end{array}$ & In water & - & 6 \\
\hline Benzene & Smoking & HITP doped Cu-HHTP-10C & $0.024-0.096 \mathrm{ppm}$ & Dry air & RT & 101 \\
\hline Chloroform, Methanol & - & Pristine graphene-Cu BTC & $2.82-22.6 \mathrm{ppm}$ & $\begin{array}{c}\text { Saturated target } \\
\text { gas vapour }\end{array}$ & RT & 103 \\
\hline
\end{tabular}

Koo et al. ${ }^{84}$ have synthesized an acetone sensor based on $\mathrm{ZnO} / \mathrm{ZnCo}_{2} \mathrm{O}_{4}$ hollow sphere derived from a bimetallic $\mathrm{ZIF}$ and functionalized with $\mathrm{Pd}$ nanoparticles, using polystyrene sphere as sacrificial template. The $\mathrm{ZnO} / \mathrm{CO}_{3} \mathrm{O}_{4}$ heterostructure was also recently studied with the synthesis of hollow polyhedron shaped particles derived from a mixture of MOFs ZIF-8 and ZIF67, for the sensing of acetone. ${ }^{85}$ Zhou et al. ${ }^{64}$ used a 3D inverted opal $\mathrm{ZnO}$ structure derived from ZIF-8, and modified with $\mathrm{Pt}$ nanoparticles for $\mathrm{H}_{2} \mathrm{~S}$ sensing application. The obtained macroporous material properties were tested at $330{ }^{\circ} \mathrm{C}$. An 
acetone sensors based on $\mathrm{ZnO@MoS} 2$ nanosheets core/shell heterojunctions derived from ZIF-8 was also recently studied. ${ }^{63}$ $\mathrm{ZnFe}_{2} \mathrm{O}_{4} /(\mathrm{Fe}-\mathrm{ZnO})$ nanocomposites derived from $\mathrm{Zn}$-based MOF, such as MOF-5 or $\left.\mathrm{Zn}_{3}\left[\mathrm{Fe}(\mathrm{CN})_{6}\right]_{2} \cdot \mathrm{xH}_{2} \mathrm{O}\right)$ were studied so as to improve the acetone sensing properties of MOF derived $\mathrm{ZnO}$ nanomaterials. ${ }^{86} \mathrm{~A}$ new method was described to add Fe to $\mathrm{ZnO}$ nanocages by immersing the chosen $\mathrm{MOF}$ in $\mathrm{Fe}\left(\mathrm{NO}_{3}\right)_{3}$ aqueous solution before annealing treatment. The $\mathrm{ZnFe}_{2} \mathrm{O}_{4} /(\mathrm{Fe}-\mathrm{ZnO})$ nanocomposite sample with $\mathrm{Fe} / \mathrm{Zn}=0.15$ mole ratio presented the best performances for acetone sensing, in air under $15 \%$ $\mathrm{RH}$, against samples with $\mathrm{Fe} / \mathrm{Zn}=0,0.05,0.10,0.20,0.25$ and 0.30 mole ratio.

\section{MOF-based sensors}

MOFs hold the advantage of very high porosity, and thereby were used for their efficient gas sensing applications. ${ }^{87}$ Recent work concerning the utilization of MOFs in the field of biomarker sensing in exhaled breath are emerging (Table 1). A study focused on the properties of MOFs composed of BTC (1,3,5-benzenetricarboxylic acid) linker and various metal sites, such as $\mathrm{Ba}(\mathrm{II}), \mathrm{Cd}(\mathrm{II}), \mathrm{Pb}(\mathrm{II})$ or $\mathrm{Zn}(\mathrm{II})$, for the sensing of ammonia. ${ }^{88}$ The conductivity of the dried materials was measured at room temperature, after the materials were compressed into small pellets. In the presence of $\mathrm{NH}_{3}$ vapor, the $\mathrm{Cd}(\mathrm{II})$ - and $\mathrm{Pb}$ (II)-based materials presented conductivities of $7.610^{-11} \mathrm{~S} \mathrm{~cm}^{-1}$ and $1.710^{-10} \mathrm{~S} \mathrm{~cm}^{-1}$ respectively, and the $\mathrm{Zn}$ based MOF showed the highest response to ammonia since the conductivity reached $8.310^{-11} \mathrm{~S} \mathrm{~cm}^{-1}$. The detection of ammonia, formaldehyde and ethanol using $\mathrm{Zn}$-based MOFs was also investigated by Reddy et al. ${ }^{89}$ At room temperature, the synthesized MOF based nicotinic acid showed a good response to ammonia at concentrations down to $10 \mathrm{ppm}$ with good longterm stability and sensitivity towards ammonia, formaldehyde and ethanol, with no suitability for acetone.

Further work on ZIF type MOFs was pursued with the investigation of ZIF-8 and ZIF-90 performances for gas sensing applications, using a biomimetic synthesis approach. ${ }^{45}$ The MOFs were used as a gravimetric-type acetone sensing material to fashion a quart crystal microbalance (QCM) device, and ZIF90 demonstrated superior results compared to ZIF-8 when tested at room temperature $\left(25{ }^{\circ} \mathrm{C}\right)$ and $35 \% \mathrm{RH}$. The ZIF-90 based sensor demonstrated good sensitivity (frequency shift of $95 \mathrm{~Hz}$ for a concentration of $1 \mathrm{ppm}$ acetone), with a detection of acetone down to $20 \mathrm{ppb}$, a good selectivity among acetone, formaldehyde, ethanol, ammonia, carbon dioxide, nitrogen monoxide, nitrogen dioxide, benzene, toluene and a rapid response and recovery time (12 s and $17 \mathrm{~s}$ respectively). ZIF-8 was post-modified with amine groups to produce two ZIF8@amine MOFs presenting sensitivity to hexanal, a potential biomarker for lung cancer, with a detection limit as low as 1 ppb. ${ }^{90}$ One study explored the selectivity of ZnO@ZIF-8 nanorods with core-shell heterostructure for gas sensing. The material exhibited definite selectivity towards formaldehyde among other VOCs such as ethanol, ammonia, acetone, toluene, and methanol. ${ }^{91}$ The detection of formaldehyde at room temperature was further enhanced using polyoxometalate (POM) to build a composite material together with $\mathrm{ZnO}$ nanorods coated with ZIF-8.92 The composite material, POM@ZIF-8@ZnO, was highly selective to formaldehyde against ethanol, and presented a high sensitivity $(0.4 \mathrm{ppm})$ and both thermal and chemical stability. The influence of an additional metal cation to the sensing sensitivity of MOF-based materials was also studied. For example, Europium $\left(\mathrm{Eu}^{3+}\right)$ was added to ZnO@MOF structures to endow the sensing material with luminescence properties, for the sensing of volatile aldehyde gases at room temperature. ${ }^{93}$ Similarly, a recent communication pointed to a luminescent Europium based MOF, $\left[\mathrm{Eu}(\mathrm{tctb})_{3}\left(\mathrm{H}_{2} \mathrm{O}\right)\right]$, capable of capturing $\mathrm{NH}_{3}$ vapour at room temperature and releasing it upon heating $\left(75^{\circ} \mathrm{C}\right) . .^{94}$ They noted the pressure dependency of $\mathrm{NH}_{3}$ adsorption, particularly with the adsorption being slower under atmospheric pressure.

An interesting optical approach is to use a colour change induced by the adsorption of the analyte. For example, the recent study of L-Glutamic acid based $\mathrm{Co}(\mathrm{II}), \mathrm{Ni}(\mathrm{II})$, and $\mathrm{Cu}(\mathrm{II})$ MOFs (L-Glu-Co, L-Glu-Ni and L-Glu-Cu respectively) evidenced a colour response of these MOF to $\mathrm{NH}_{3}$ vapor. ${ }^{95}$ Several metal complexes were studied for luminescence vapochromismbased gas sensors. Zhang et al. ${ }^{96}$ questioned and studied the potential of $d^{6}, d^{8}$ or $d^{10}$ metal complexes for this application. However, the number of such complexes which present a good selectivity towards a specific VOC is limited, and the quantification of the analyte detected is another issue. Nevertheless, the perspective of new materials based on such metal complexes remains an interesting path to be reflected upon. As a potential approach for the development of new materials, the authors propose the use of vapochromic $d^{6}, d^{8}$ or $\mathrm{d}^{10}$ metal complexes to build metallic coordination systems with infinitely extended structures. They also suggest to combine the desired metal complexes into open frameworks, via the doping or intercalation of the coordination metal anions or cations with discrete structures into cationic or anionic layered compounds of the targeted framework material as another possible approach. On this topic, $\mathrm{Hu}$ et al. ${ }^{97}$ published a detailed screening of luminescent MOFs for sensing application and the detection of explosives. In the scope of the detection of biomarkers using optical detection, Cd-based MOFs, namely $\left(\left[\mathrm{Cd}_{3}(\mathrm{~L})\left(\mathrm{H}_{2} \mathrm{O}\right)_{2}(\mathrm{DMF})_{2}\right] .5 \mathrm{DMF}\right)_{n}$ and $\left(\left[\mathrm{Cd}_{3}(\mathrm{~L})(\mathrm{dib})\right] .3 \mathrm{H}_{2} \mathrm{O} .5 \mathrm{DMA}\right)_{n}$ were studied for the detection of acetone as fluorescent sensors, thanks to fluorescence quenching upon analyte adsorption. ${ }^{46}$ For acetone contents of 0.3 vol\% and 1.0 vol\%, the MOFs fluorescence were decreased by $50 \%$ and almost entirely quenched, respectively, promising an excellent potential for acetone detection application. Newly designed bimetallic MOFs, $\mathrm{Al}_{x} \mathrm{Fe}_{1-\mathrm{x}}-\mathrm{MIL}(\mathrm{x}=0.05,0.1$, and 0.2 ), were presented for the fluorescence detection of $\mathrm{H}_{2} \mathrm{~S}$ in an aqueous system. ${ }^{98} \mathrm{As}$ the replacement of trace amounts of $\mathrm{Al}^{3+}$ by $\mathrm{Fe}^{3+}$ in MOF Al-MIL53- $\mathrm{NH}_{2}$ provokes a florescence quenching in the bimetallic $\mathrm{MOF}$, it was then possible to observe an increase in the fluorescence following the detection of $\mathrm{H}_{2} \mathrm{~S}$. Another example is the selective detection of $\mathrm{NH}_{3}$ through the use of $\mathrm{Zn}_{2}$ (TCPE) and $\mathrm{Mg}(\mathrm{DHBDC})$ at $100^{\circ} \mathrm{C}$ using the ligands fluorescent 
properties ( $23 \mathrm{~nm}$ fluorescence shift). ${ }^{99}$ The detection was also tested at room temperature but the materials then showed no selectivity towards $\mathrm{NH}_{3}$. The detection of nitrite gas using MOFs photoluminescence was recently approached by Tapangpan et al. ${ }^{6}$ via the synthesis of a Tb-based MOF, $\left[\mathrm{Tb}_{2}(\mathrm{TTHA})\left(\mathrm{H}_{2} \mathrm{O}\right)_{4}\right] \cdot 9 \mathrm{H}_{2} \mathrm{O} \quad\left(\mathrm{H}_{6} \mathrm{TTHA}=1,3,5\right.$-triazine-2,4,6triaminehexaacetic acid). As the photoluminescent emission of the ligand can be turned off following the coordination with nitrite, their research demonstrated the use of this property to selectively identify the presence of nitrite in water. Although the study required large amounts of analyte (3-12 $\mathrm{gg}$ of nitrite) the colorimetric detection of nitrite was possible in the presence of water, and the use of a porous material might be promising for nitrite detection in the scope of breath analysis. Another MOF based on a rare-earth element was studied for the development of a chemical capacitive sensor thin film (Fig. 3). ${ }^{44}$ The naphthalene-based MOF, namely (NDC-Y-fcu-MOF), demonstrated a good sensitivity (100 ppb) and selectivity at room temperature towards $\mathrm{NH}_{3}$ among other gas such as methane, nitrogen dioxide, hydrogen, and toluene.

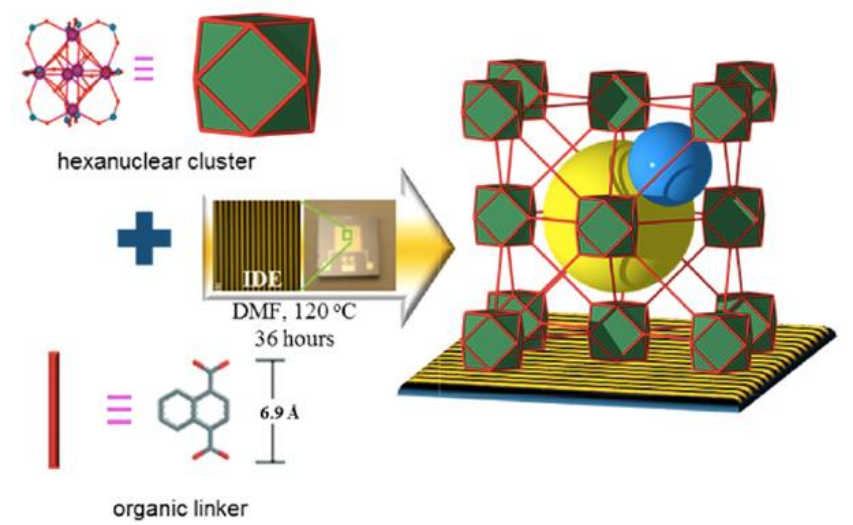

Figure 3. Example of MOF-based sensor with NaphthaleneBased fcu-MOF (NDC-Y-fcu-MOF) Thin Film on IDE Substrate. Reprinted with permission from A. H. Assen, O. Yassine, O. Shekhah, M. Eddaoudi and K. N. Salama, ACS Sens, 2017, 2, 1294-1301. ${ }^{44}$ Copyright (2020) American Chemical Society.

The use of MOFs thin films combined with QCM and siliconbased microcantilever sensors was assessed for an on-site and real-time detection of VOCs. ${ }^{100}$ As the weight detection sensors allowed to monitor the adsorption/desorption of the gases, the variable pore size offered by the MOFs structure led to the selectivity of specific analytes. The sensitivity to various gases (such as ethanol, acetone, toluene, $n$-octane, $n$-hexane, $n$ hexanol, $n$-heptane, $n$-octanol, $o$-xylene, $m$-xylene, and $p$ xylene) was tested for $\mathrm{Cu}_{3}(\mathrm{btc})_{2}$ and $\mathrm{Zn}_{4} \mathrm{O}(\mathrm{bdc})_{3}$ at $60{ }^{\circ} \mathrm{C}$. The two MOFs presented different responses towards the VOCs, among which $\mathrm{Cu}_{3}(\mathrm{btc})_{2}$ could notably detect toluene at a concentration down to $1 \mathrm{ppm}$. Cu-based conductive MOF thin films were recently synthesized using a dual-ligand design strategy for the modulation of the material's sensitivity and selectivity. ${ }^{101}$ The chemiresistive gas sensors were studied for the detection of toxic or explosive gases, including ammonia, at room temperature. The capacity of $\mathrm{Cu}$-based MOFs to detect VOCs (acetone, ethanol, methanol, toluene) was also tested with $\mathrm{Cu}(\mathrm{bdc}) \cdot \mathrm{xH}_{2} \mathrm{O}$, grown on interdigitated electrodes, at room temperature. ${ }^{102}$ The four analytes studied triggered a linear change of capacity which increased in function of analyte concentration. This linear variation was also observed for toluene at low concentration (125-500 ppm). The tuning of the sensitivity and selectivity of MOF-based chemoresistive biomarker sensors (methanol, ethanol, chloroform, acetone, acetonitrile and tetrahydrofuran) was recently studied via the hybridization of pristine graphene and MOFs. The studied nanocomposite materials were based on CUBTC, UiO-66 and ZIF-8. The experiments were conducted at room temperature and the materials showed higher selectivity towards methanol, and chloroform for CUBTC. ${ }^{103}$

\section{MOF-based preconcentrators}

Metal oxide-based sensors have demonstrated excellent performances. Nevertheless, it has been pointed out in many researches that their sensitivity, and sometimes selectivity, is dependent on the temperature. These parameters increase with the temperature, while a low working temperature would be more suitable for a portable device. ${ }^{43}$ Through the use of MOFs as pre-concentrators, the sensing layer could work at lower temperature since with higher concentration of analyte directed to the sensing layer, the temperature can be lowered along with the sensitivity, as the use of a pre-concentrator takes care of concentrating the desired analyte for the detection thanks to an adsorption process. As presented, the amazing high porosity of MOFs can be used as a way to capture gases and concentrate them onto the sensing layer. In addition, the adjustable pore size of MOFs, through the design of their structure by the choice of ligands and metal center, permits an enhanced selectivity towards the target analyte. Both of these properties lead to very efficient pre-concentrators. For example, micro preconcentrators were newly designed using MOF- 5 embedded on nickel foam. ${ }^{104}$ When tested on trace level mixture of gases (benzene, toluene, ethylbenzene, and xylene) in dry $\mathrm{N}_{2}$ at room temperature, they demonstrated significantly higher preconcentration factors and lower pressure drops than commercial adsorbents, and a low desorption temperature (150 $\left.{ }^{\circ} \mathrm{C}\right)$. Yu et al. ${ }^{105}$ have investigated the use of MOFs as preconcentrators, combined with gas chromatography. Three MOFs, ZIF-7, UiO-66 and MOF-5 were studied for the sorption of acetone and isopropanol in the exhaled breath of diabetics before analysis by gas chromatography, amongst which UiO-66 was found to be the most appropriate sorbent for the application with a surface area of $708 \mathrm{~m}^{2} \mathrm{~g}^{-1}$. The MOFs were each packed in a quartz tube, plugged with copper wire mesh and glass wool, and aged for $1 \mathrm{~h}$ at $300{ }^{\circ} \mathrm{C}$ under $\mathrm{N}_{2}$ before sorption measurements. The samples used for the tests were collected in suitable bags from diabetic patients and healthy volunteers. The durability of UiO-66 was determined over 120 adsorption cycles of the analyte and showed no significant loss in adsorption capacity. In order to achieve the best efficiency, the best flow rate was estimated and set at $0.4 \mathrm{~L} \mathrm{~min}^{-1}$, the 
desorption time was optimized at $5 \mathrm{~min}$, and the best desorption temperature was $240{ }^{\circ} \mathrm{C}$ for UiO-66, $280^{\circ} \mathrm{C}$ and 260 ${ }^{\circ} \mathrm{C}$ for ZIF-7 and MOF-5 respectively. UiO-66 was again studied more recently as a pre-concentrator for acetone gas sensors coupled with coupled with a rapid cataluminescence (CTL) sensor. ${ }^{106}$ The use of UiO-66 allowed for an enhanced CTL emission, and the whole system presented a detection limit of acetone down to $2.79 \mathrm{ppm}$ with good selectivity. The optimal detection temperature was estimated at $253{ }^{\circ} \mathrm{C}$ and the best flow rate at $200 \mathrm{~mL} \mathrm{~min}^{-1}$ for the carrier gas and $400 \mathrm{~mL} \mathrm{~min}^{-1}$ for the sampling flow rate. Stainless steel fibre coated with ZIF7 using a sol-gel solution was studied for the extraction of aldehydes in exhaled breath sampled from lung cancer patients for post-analysis by gas chromatography. ${ }^{107}$ The synthesized material was tested with a desorption temperature of $250{ }^{\circ} \mathrm{C}$ with breath samples from lung cancer patients and from healthy volunteers. The experimental parameters were optimized, with a desorption time set for $2 \mathrm{~min}$, and the extraction time and temperature were set at $15 \mathrm{~min}$ and $50{ }^{\circ} \mathrm{C}$ respectively. The ZIF7 coated fibre exhibited good sensitivity on real samples and high recovery, and, with a small decrease, the material demonstrated a good durability over 150 cycles.

Surface-enhanced Raman scattering (SERS) is an analysis technique which present the advantage of allowing the detection of trace or even single molecule. Using MOF as a supporting net for VOCs is a novel approach to enhance the quantitative detection of biomarkers using SERS. In a similar approach to concentrate the analyte pre-analysis, MIL-100(Fe) was used as SERS-active substrate for high sensitivity detection of toluene, with a detection limit of $2.5 \mathrm{ppm} .{ }^{108}$ The detection limit dropped down to $0.48 \mathrm{ppb}$ when the MIL-100(Fe) was combined with a gold nanoparticle film. In addition, the MOF helped distinguish different kind of VOCs and was successfully used for the sensitive detection of lung cancer biomarkers (e.g. 4-ethylbenzaldehyde, acetone, isopropanol). The SERS-active MIL-100(Fe) platform also presented the advantage to offer the possibility to be modified through metal doping to form different active sites to target a higher diversity of VOCs. For similar application, gold superparticles (GSPs) were coated with ZIF-8. ${ }^{109}$ As the MOF serves as preconcentrator, gaseous aldehydes react with 4-aminothiophenol pre-grafted on GSPs and are detected within a detection limit of $10 \mathrm{ppb}$. The GSPs@ZIF-8 also present the very interesting capability to selectively detect trace cancer biomarkers in gas mixtures.

\section{Conclusion}

The present frontier review aimed to offer an overview of the recent interest of porous materials like MOFs in regard to their application for gas sensing applied to the analysis of exhaled breath for non-invasive methods of diseases identification. The adsorption/desorption and quantification of biomarkers through efficient and highly selective gas sensors has been actively studied over the past decade and is still an active field of research. Understandably, the development of a noninvasive and non-binding method to test patients for diseases using a portable device is a very attractive idea. However, the challenges to overcome in order to develop such sensors are not among the least ones. The device should be easy to distribute, portable, and work on real, on-site, conditions. For example, in a practitioner's office, or at a patient's residence (e.g. for diabetics). Furthermore, the selectivity of the sensing material must be high as exhaled breath samples contain very high humidity and numerous interfering compounds. It should also be highly sensitive and selective to detect the biomarker of interest among the rich composition of the human breath. MOFs and porous materials give rise to a growing interest in this field as their nanostructure allows a pre-selectivity and preconcentration of the target gases. Combined with SERS technique, MOF can be used as active substrates to capture and enhance the Raman signal of targeted biomarkers. This novel approach is promising for precise detection of biomarkers in exhaled breath. MOFs are being considered as efficient preconcentrators but they are also interesting as template and as starting material for the synthesis of metal-oxide based efficient sensors. As for MOFs based sensors for biomarkers detection in breath, recent studies are still emerging, proposing innovative approaches such as MOF ligand post-modification or through the synthesis of MOF-based nanocomposites.

\section{Author contributions}

L.A. wrote the frontier review and prepared the table and figures. N.D., C.G. and S.B. have critically and scientifically revised the manuscript.

\section{Conflicts of interest}

There are no conflicts to declare.

\section{Acknowledgements}

This work was supported by the CNRS (UMR UB-CNRS 6302, the "Université Bourgogne Franche-Comté (UBFC)", and the "Conseil Régional de Bourgogne" through the Plan d'Actions Régional pour I'Innovation (PARI II CDEA) and the European Union through the PO FEDER-FSE Bourgogne 2014/2020 (via the CoMICS program, Chemistry of Molecular Interactions: Catalysis \& Sensors and the ISITE CO2DECIN).

\section{References}

1. D. Guo, D. Zhang, L. Zhang and G. Lu, Sens. Actuators B, 2012, 173, 106-113.

2. C. Deng, J. Zhang, X. Yu, W. Zhang and X. Zhang, J. Chromatogr. B: Anal. Technol. Biomed. Life Sci., 2004, 810, 269-275.

3. A. M. Diskin, P. pan I and D. Smith, Physiol. Meas., 2003, 24, 107-119.

4. Z. H. Endre, J. W. Pickering, M. K. Storer, W. P. Hu, K. T. Moorhead, R. Allardyce, D. O. McGregor and J. M. Scotter, Physiol. Meas., 2011, 32, 115-130.

5. S. Davies, P. Spanel and D. Smith, Kidney Int., 1997, 52, 223228. 
6. P. Tapangpan, K. Panyarat, C. Chankaew, K. Grudpan and A Rujiwatra, Inorg. Chem. Commun., 2020, 111, 107627.

7. A. Diouf, N. El Bari and B. Bouchikhi, Talanta, 2020, 209, 120577.

8. T. Amou, D. Hinode, M. Yoshioka and D. Grenier, Int. J. Dent. Hyg., 2014, 12, 145-151.

9. K. Eto, T. Asada, K. Arima, T. Makifuchi and H. Kimura, Biochem. Biophys. Res. Comm., 2002, 293, 1485-1488.

10. Y. Guo, X. Tian, X. Wang and J. Sun, Sens. Actuators B, 2019, 293, 136-143.

11. Y. Liu, Z. Wei, J. Zhou and Z. Ma, Nat. Commun., 2019, 10, 5361.

12. Y. Y. Broza, R. Vishinkin, O. Barash, M. K. Nakhleh and H. Haick, Chem. Soc. Rev., 2018, 47, 4781-4859.

13. S. Das and M. Pal, J. Electrochem. Soc., 2020, 167, 037562.

14. C. Di Natale, R. Paolesse, E. Martinelli and R. Capuano, Anal. Chim. Acta., 2014, 824, 1-17.

15. K. H. Kim, S. A. Jahan and E. Kabir, TrAC Trends Anal. Chem., 2012, 33, 1-8.

16. G. Konvalina and H. Haick, Acc. Chem. Res., 2014, 47, 66-76.

17. A. Rydosz, Sensors, 2018, 18, 2298/1-2298/14.

18. X. Zou, G. Zhu, I. J. Hewitt, F. Sun and S. Qiu, Dalton Trans., 2009, 3009-3013.

19. C. Di Natale, A. Macagnano, E. Martinelli, R. Paolesse, G. D'Arcangelo, C. Roscioni, A. Finazzi-Agrò and A. D'Amico, Biosens. Bioelectron., 2003, 18, 1209-1218.

20. P. J. Mazzone, X.-F. Wang, Y. Xu, T. Mekhail, M. C. Beukemann, J. Na, J. W. Kemling, K. S. Suslick and M. Sasidhar, J. Thorac. Oncol., 2012, 7, 137-142.

21. G. Peng, U. Tisch, O. Adams, M. Hakim, N. Shehada, Y. Y. Broza, S. Billan, R. Abdah-Bortnyak, A. Kuten and H. Haick, Nat. Nanotechnol.,, 2009, 4, 669-673.

22. X. Sun, K. Shao and T. Wang, Anal. Bioanal. Chem., 2016, 408, $2759-2780$.

23. J. Zhou, Z. A. Huang, U. Kumar and D. D. Y. Chen, Anal. Chim. Acta., 2017, 996, 1-9.

24. R. Thriumani, A. Zakaria, Y. Z. H.-Y. Hashim, A. I. Jeffree, K. M. Helmy, L. M. Kamarudin, M. I. Omar, A. Y. M. Shakaff, A. Abdul Hamid and K. C. Persaud, BMC Cancer, 2018, 18, 362/1-362/17.

25. T. Saidi, M. Moufid, K. de Jesus Beleño-Saenz, T. G. Welearegay, N. El Bari, A. Lisset Jaimes-Mogollon, R. Ionescu, J. E. Bourkadi, J. Benamor, M. El Ftouh and B. Bouchikhi, Sens. Actuators B, 2020, 311, 127932.

26. R. Pesesse, P. H. Stefanuto, F. Schleich, R. Louis and J. F. Focant, J. Chromatogr. B: Anal. Technol. Biomed. Life Sci., 2019, 11141115, 146-153.

27. E. Kovalska, P. Lesongeur, B. T. Hogan and A. Baldycheva, Nanoscale, 2019, 11, 2476-2483.

28. S. Kort, M. M. Tiggeloven, M. Brusse-Keizer, J. W. Gerritsen, J. H. Schouwink, E. Citgez, F. H. C. de Jongh, S. Samii, J. van der Maten, M. van den Bogart and J. van der Palen, Lung Cancer, 2018, 125, 223-229.

29. G. Gregis, S. Schaefer, J.-B. Sanchez, V. Fierro, F. Berger, I. Bezverkhyy, G. Weber, J.-P. Bellat and A. Celzard, Mater. Chem. Phys., 2017, 192, 374-382.

30. R. de Vries, M. Muller, V. van der Noort, W. Theelen, R. D. Schouten, K. Hummelink, S. H. Muller, M. Wolf-Lansdorf, J. W. F. Dagelet, K. Monkhorst, A. H. Maitland-van der Zee, P. Baas, P. J. Sterk and M. M. van den Heuvel, Ann. Oncol., 2019, 30, 1660-1666.

31. Q. Chen, Z. Chen, D. Liu, Z. He and J. Wu, ACS Appl. Mater. Interfaces, 2020, 12, 17713-17724.
32. J. Li, Y. Peng and Y. Duan, Crit. Rev. Oncol. Hematol., 2013, 87, 28-40.

33. A. A. Mäkitie, A. Almangush, O. Youssef, M. Metsälä, S. Silén, I. J. Nixon, M. Haigentz Jr, J. P. Rodrigo, N. F. Saba, V. Vander Poorten and A. Ferlito, Head \& Neck, 2020, 42, 787-793.

34. Y. Chen, Y. Zhang, F. Pan, J. Liu, K. Wang, C. Zhang, S. Cheng, L. Lu, W. Zhang, Z. Zhang, X. Zhi, Q. Zhang, G. Alfranca, J. M. de la Fuente, D. Chen and D. Cui, ACS Nano, 2016, 10, 8169-8179.

35. R. S. Andre, R. C. Sanfelice, A. Pavinatto, L. H. C. Mattoso and D. S. Correa, Mater. Des., 2018, 156, 154-166.

36. T. Islamoglu, Z. Chen, M. C. Wasson, C. T. Buru, K. O. Kirlikovali, U. Afrin, M. R. Mian and O. K. Farha, Chem. Rev., 2020, 120, 8130-8160.

37. H.-Y. Li, S.-N. Zhao, S.-Q. Zang and J. Li, Chem. Soc. Rev., 2020, 49, 6364-6401.

38. Y. Li, A.-S. Xiao, B. Zou, H.-X. Zhang, K.-L. Yan and Y. Lin, Polyhedron, 2018, 154, 83-97.

39. A. Sturluson, R. Sousa, Y. Zhang, M. T. Huynh, C. Laird, A. H. P. York, C. Silsby, C.-H. Chang and C. M. Simon, ACS Appl. Mater. Interfaces, 2020, 12, 6546-6564.

40. X. Zou, J.-M. Goupil, S. Thomas, F. Zhang, G. Zhu, V. Valtchev and S. Mintova, J. Phys. Chem. C, 2012, 116, 16593-16600.

41. P. Kumar, A. Deep, K.-H. Kim and R. J. C. Brown, Prog. Polym. Sci.,, 2015, 45, 102-118.

42. H. Naderi, S. Hajati, M. Ghaedi, K. Dashtian and M. M. Sabzehmeidani, Appl. Surf. Sci., 2020, 501, 144270.

43. P. Srinivasan, A. J. Kulandaisamy, G. K. Mani, K. J. Babu, K. Tsuchiya and J. B. B. Rayappan, RSC Adv., 2019, 9, 3022630239.

44. A. H. Assen, O. Yassine, O. Shekhah, M. Eddaoudi and K. N. Salama, ACS Sens., 2017, 2, 1294-1301.

45. D. Zhang, Y. Fan, G. Li, W. Du, R. Li, Y. Liu, Z. Cheng and J. Xu, Sens. Actuators B, 2020, 302, 127187.

46. F.-Y. Yi, W. Yang and Z.-M. Sun, J. Mater. Chem., 2012, 22, 23201-23209.

47. Y.-Y. Lv, J. Wu and Z.-K. Xu, Sens. Actuators B, 2010, 148, 233239.

48. R. Zimmerman, L. Basabe-Desmonts, F. van der Baan, D. N. Reinhoudt and M. Crego-Calama, J. Mater. Chem., 2005, 15, 2772-2777.

49. B. Behera, R. Joshi, G. K. Anil Vishnu, S. Bhalerao and H. J. Pandya, J. Breath Res., 2019, 13, 24001.

50. S. Dragonieri, G. Pennazza, P. Carratu and O. Resta, Lung, 2017, 195, 157-165.

51. P. Le Maout, J.-L. Wojkiewicz, N. Redon, C. Lahuec, F. Seguin, L. Dupont, S. Mikhaylov, Y. Noskov, N. Ogurtsov and A. Pud, Sens. Actuators B, 2018, 274, 616-626.

52. C. S. L. Koh, H. K. Lee, X. Han, H. Y. F. Sim and X. Y. Ling, Chem. Commun., 2018, 54, 2546-2549.

53. H. Zhao, L. Liu, X. Lin, J. Dai, S. Liu, T. Fei and T. Zhang, ACS Sens., 2020, 5, 346-352.

54. S. Majumdar, K. Sarmah and D. Mahanta, ACS Appl. Polym. Mater., 2020, 2, 1933-1942.

55. Y. Chen, Q. Li, Z. Xie and X. A. Fu, J. Chromatogr. B: Anal. Technol. Biomed. Life Sci., 2019, 1106-1107, 58-63.

56. M.-Y. Chuang, Y.-T. Lin, T.-W. Tung, L.-Y. Chang, H.-W. Zan, H.F. Meng, C.-J. Lu and Y.-T. Tao, Sens. Actuators B, 2018, 260, 593-600.

57. L. Liu, T. Fei, X. Guan, X. Lin, H. Zhao and T. Zhang, Sens. Actuators B, 2020, 320, 128318. 
58. A. Ma, H. J. Park, J. H. Seo, K. Y. Jang, H. K. Lee, D. Y. Kim, J. E. Lee, K. M. Nam and D.-S. Lee, Sens. Actuators B, 2020, 308, 127698

59. M. Masikini, M. Chowdhury and O. Nemraoui, J. Electrochem. Soc., 2020, 167, 037537.

60. P. T. Moseley, Meas. Sci. Technol., 2017, 28, 082001/1082001/15

61. T. A. Righettoni M and S. E. Pratsinis, Anal. Chem., 2010, 82, 3581-3587.

62. W. Quan, X. Min, J. Qiu, W. Qin, H. Wang, T. Pan, S. Cheng, X. Chen, X. Hu, W. Zhang, R. Tian, P. Ji, H. Zheng and X. Wang, Sensors, 2020, 20, 1150.

63. X. Chang, X. Li, X. Qiao, K. Li, Y. Xiong, X. Li, T. Guo, L. Zhu and Q. Xue, Sens. Actuators B, Chem, 2020, 304, 127430.

64. T. Zhou, R. Zhang, Y. Wang and T. Zhang, Sens. Actuators $B$, 2019, 281, 885-892.

65. Y. Xiong, X. Chang, X. Qiao, K. Li, L. Zhu, F. Xia, X. Li, Q. Zheng, W. Xing and Q. Xue, Sens. Actuators B, 2019, 300, 127011.

66. X.-Z. Song, L. Qiao, K.-M. Sun, Z. Tan, W. Ma, X.-L. Kang, F.-F. Sun, T. Huang and X.-F. Wang, Sens. Actuators B, 2018, 256, 374-382.

67. H. Gong, C. Zhao, G. Niu, W. Zhang and F. Wang, Research, 2020, 2020, 2196063.

68. J. Zhang, X. Jia, D. Lian, J. Yang and H. Song, J. Mater. Sci.: Mater. Electron., 2020, 31, 15446-15455.

69. Y. Jian, W. Hu, Z. Zhao, P. Cheng, H. Haick, M. Yao and W. Wu, N Nano-Micro Lett., 2020, 12, doi:10.1007/s40820-020-04075.

70. Z. Pang, Q. Nie, P. Lv, J. Yu, F. Huang and Q. Wei, Nanotechnology, 2017, 28, 225501/1-225501/10.

71. S. Bai, Y. Tian, M. Cui, J. Sun, Y. Tian, R. Luo, A. Chen and D. Li, Sens. Actuators B, 2016, 226, 540-547.

72. L.-H. Xu and T.-M. Wu, J. Mater. Sci.: Mater. Electron., 2020, 31, 7276-7283.

73. V. Kumar, A. Mirzaei, M. Bonyani, K.-H. Kim, H. W. Kim and S. S. Kim, TrAC Trends Anal. Chem., 2020, 115938.

74. L. Wang, H. Huang, S. Xiao, D. Cai, Y. Liu, B. Liu, D. Wang, C. Wang, H. Li, Y. Wang, Q. Li and T. Wang, ACS Appl. Mater Interface, 2014, 6, 14131-14140.

75. E. Pargoletti, U. H. Hossain, I. Di Bernardo, H. Chen, T. Tran-Phu, G. L. Chiarello, J. Lipton-Duffin, V. Pifferi, A. Tricoli and G. Cappelletti, ACS Appl. Mater Interfaces, 2020, 39549-39560.

76. S. J. Choi, I. Lee, B. H. Jang, D. Y. Youn, W. H. Ryu, C. O. Park and I. D. Kim, Anal. Chem., 2013, 85, 1792-1796.

77. J.-S. Jang, S.-J. Choi, S.-J. Kim, M. Hakim and I.-D. Kim, Adv. Funct. Mater., 2016, 26, 4740-4748.

78. Y. Xu, L. Zheng, C. Yang, X. Liu and J. Zhang, Sens. Actuators B, 2020, 304, 127237.

79. C. Zhang, L. Li, L. Hou and W. Chen, Sens. Actuators B, 2019, 291, 130-140.

80. W. T. Koo, J. S. Jang, S. J. Choi, H. J. Cho and I. D. Kim, ACS Appl. Mater. Interfaces, 2017, 9, 18069-18077.

81. X. Zhou, X. Lin, S. Yang, S. Zhu, X. Chen, B. Dong, X. Bai, X. Wen, L. Geyu and H. Song, Sens. Actuators B, 2020, 309, 127802.

82. S. Zhu, L. Xu, S. Yang, X. Zhou, X. Chen, B. Dong, X. Bai, G. Lu and H. Song, J. Colloid. Interface Sci., 2020, 569, 358-365.

83. W. T. Koo, S. J. Choi, J. S. Jang and I. D. Kim, Sci. Rep., 2017, 7, 45074.

84. W. T. Koo, S. Yu, S. J. Choi, J. S. Jang, J. Y. Cheong and I. D. Kim, ACS Appl. Mater. Interfaces, 2017, 9, 8201-8210.

85. D. Zhang, Z. Yang, Z. Wu and G. Dong, Sens. Actuators B, 2019, 283, 42-51.
86. E. Cao, Z. Guo, G. Song, Y. Zhang, W. Hao, L. Sun and Z. Nie, Sens. Actuators B, 2020, 325, 128783.

87. A. Amini, S. Kazemi and V. Safarifard, Polyhedron, 2020, 177, 114260.

88. K. Sel, S. Demirci, O. F. Ozturk, N. Aktas and N. Sahiner, Microelectron. Eng., 2015, 136, 71-76.

89. A. J. Mohan Reddy, N. K. Katari, P. Nagaraju and S. Manabolu Surya, Mater. Chem. Phys., 2020, 241, 122357.

90. Y. Xia, Y. Hong, R. Geng, X. Li, A. Qu, Z. Zhou and Z. Zhang, ACS Omega, 2020, 5, 3478-3486.

91. H. Tian, H. Fan, M. Li and L. Ma, ACS Sens., 2015, 1, 243-250.

92. P. Wang, X. Zou, H. Tan, S. Wu, L. Jiang and G. Zhu, J. Mater. Chem. C, 2018, 6, 5412-5419.

93. X.-Y. Xu and B. Yan, J. Mater. Chem. A, 2017, 5, 2215-2223.

94. T. N. Nguyen, I. M. Harreschou, J.-H. Lee, K. C. Stylianou and D. W. Stephan, Chem. Commun., 2020, 56, 9600-9603.

95. M. Can, S. Demirci, A. K. Sunol and N. Sahiner, Microporous Mesoporous Mater., 2020, 309, 110533.

96. X. Zhang, B. Li, Z.-H. Chen and Z.-N. Chen, J. Mater. Chem., 2012, 22, 11427-11441.

97. Z. Hu, B. J. Deibert and J. Li, Chem. Soc. Rev., 2014, 43, 58155840.

98. Z. Zhu, V. Natarajan and W.-N. Wang, J. Sol. State Chem., 2020, 288, 121434.

99. N. B. Shustova, A. F. Cozzolino, S. Reineke, M. Baldo and M. Dinca, J. Am. Chem. Soc., 2013, 135, 13326-13329.

100. H. Yamagiwa, S. Sato, T. Fukawa, T. Ikehara, R. Maeda, T. Mihara and M. Kimura, Sci. Rep., 2014, 4, 6247.

101. A.-Q. Wu, W.-Q. Wang, H.-B. Zhan, L.-A. Cao, X.-L. Ye, J.-J. Zheng, P. N. Kumar, K. Chiranjeevulu, W.-H. Deng, G.-E. Wang, M.-S. Yao and G. Xu, Nano Res., 2020, doi: 10.1007/s12274020-2823-8.

102. C. Sapsanis, H. Omran, V. Chernikova, O. Shekhah, Y. Belmabkhout, U. Buttner, M. Eddaoudi and K. N. Salama, Sensors, 2015, 15, 18153-18166.

103. T. T. Tung, M. T. Tran, J.-F. Feller, M. Castro, T. Van Ngo, K. Hassan, M. J. Nine and D. Losic, Carbon, 2020, 159, 333-344.

104. J. Lee, J. Lee and S.-H. Lim, J. Hazard. Mater., 2020, 392, 122145.

105. L. Q. Yu, F. H. Su, M. Y. Ma and Y. K. Lv, Mikrochim. Acta, 2019, $186,1-6$

106. X. Huang, Z. Huang, L. Zhang, R. Liu and Y. Lv, Sens. Actuators B, 2020, 312, 127952.

107. L. Q. Yu, L. Y. Wang, F. H. Su, P. Y. Hao, H. Wang and Y. K. Lv, Mikrochim. Acta, 2018, 185, 1-7.

108. J.-H. Fu, Z. Zhong, D. Xie, Y.-J. Guo, D.-X. Kong, Z.-X. Zhao, Z.-X. Zhao and M. Li, Angew. Chem. Int. Ed., 2020, doi:10.1002/anie.202002720.

109. X. Qiao, B. Su, C. Liu, Q. Song, D. Luo, G. Mo and T. Wang, Adv. Mater., 2018, 30, 1702275. 